\title{
Comparative genetic variability between broodstock and offspring populations of Korean starry flounder used for stock enhancement in a hatchery by using microsatellite DNA analyses
}

\author{
H.S. An, E.-H. Shin, J.W. Lee, M.M. Nam, J.I. Myeong and C.M. An \\ Biotechnology Research Division, \\ National Fisheries Research and Development Institute, Busan, Korea \\ Corresponding author: H.S. An \\ E-mail: hsan97@korea.kr
}

Genet. Mol. Res. 12 (4): 6319-6330 (2013)

Received June 19, 2013

Accepted September 19, 2013

Published December 4, 2013

DOI http://dx.doi.org/10.4238/2013.December.4.19

\begin{abstract}
Korean starry flounder, Platichthys stellatus (Pleuronectidae), is one of the most economically important fishery resources in Korea. We investigated the effect of current artificial reproduction in a hatchery facility, genetic divergence between the broodstock and their offspring populations of starry flounder in a hatchery strain to be stocked into natural sea areas was accessed using 9 polymorphic nuclear microsatellite DNA loci. High levels of polymorphism were observed between the 2 populations. A total of 96 alleles were detected at the loci, with some alleles being unique in the broodstock. Allelic variability ranged from 8 to 17 in the broodstock and from 7 to 12 in the offspring population. Average observed and expected heterozygosities were estimated at 0.565 and 0.741 in the broodstock samples and 0.629 and 0.698 in the offspring population, respectively. Although no statistically significant reductions were found
\end{abstract}


in heterozygosity or allelic diversity in the offspring population, a considerable loss of rare alleles was observed in the offspring population compared with that in the broodstock. Significant genetic difference was detected between the broodstock and offspring populations $\left(F_{\mathrm{ST}}\right.$ $=0.021, \mathrm{P}<0.05)$. These results suggest that more intensive breeding practices for stock enhancement might have resulted in a further decrease of genetic diversity. Thus, genetic variations of broodstock and progeny should ideally be monitored in both breeding and release programs as a routine hatchery operation in order to improve the starry flounder hatchery management. This information might be useful for fishery management and aquaculture industry of $P$. stellatus.

Key words: Korean starry flounder; Platichthys stellatus; Broodstock; Artificial reproduction; Microsatellite loci; Stock enhancement

\section{INTRODUCTION}

Korean starry flounder, Platichthys stellatus (Pleuronectiformes: Pleuronectidae), is a cold water marine fish found in the North Pacific, spanning Korea, Japan, Sea of Okhotsk, Bering Sea, and Alaska to California (Kang et al., 2012). In Korea, P. stellatus is an important fishery resource for prospective aquaculture diversification. However, the annual catch of this fish has fluctuated and continuously declined. Increasing the harvest yield requires that efforts should be focused on aquaculture production and stock enhancement. Recently, the aquaculture industry of starry flounder farming is booming in areas surrounding the East Sea of Korea because of the establishment of a mass production technique for seedlings. Due to the steady production decrease, a stock enhancement program that involves the release of hatchery-reared juveniles to the natural environment was started by the Korean government in the early 2000 and is still ongoing (KFRA, 2010; NFRDI, 2010).

Starry flounder farming is a key part of aquaculture in eastern Korea. Seeds of starry flounder in this region are produced exclusively in hatcheries. Typically, almost all starry flounder hatcheries maintain hundreds of males and females from both wild-caught and captive-cultured sources of $P$. stellatus as the broodstock for artificial reproduction for stock enhancement. However, breeding has persisted for multiple generations with little introduction of exotic broodstocks, due to the difficulty in collecting large numbers of sexually mature wild P. stellatus. Furthermore, in practice, offspring starry flounders usually breed without any consideration to the mating system. Thus, there were concerns that genetic variability in hatchery stocks might have been lost during artificial propagation. Loss of genetic variation leads to potential harmful effects on various commercially important traits such as survival and growth, which can damage the aquaculture process (Allendorf and Pyman, 1987). Intensive stocking practices with inappropriate hatchery procedures might result in detrimental genetic impacts on the wild stock accompanied by risk to the continued exploitation of the resource. The genetic diversity of artificial seeds is generally lower than that of wild populations, due to unconscious selection and the limited number of parents used to produce subsequent generations in a hatchery (Kohlmann et al., 2005; An et al., 2011b, 2013; Wang et al., 2011). Genetic diversity of wild and cultivated P. stellatus stocks was 
recently reported (An et al., 2011a). Research data on the standard breeding practices in a hatchery are needed for maintaining cultivated stocks for the conservation of diversity and minimization of inbreeding for future aquaculture development. However, little effort has been undertaken to understand genetic divergence between the broodstock and their offspring populations of Korean starry flounder produced in a hatchery facility, despite the concerted efforts aimed at artificial propagation. Therefore, genetic diversity should ideally be monitored during both breeding and release programs as a routine hatchery operation in order to improve starry flounder hatchery management.

Molecular markers have proved to be an exceptional indicator of genetic variation within and between populations of many fishery animals, including fish (Yoon et al., 2011; Han et al., 2012; Hong et al., 2012; Lee and Hur, 2012). Especially, microsatellite (MS) DNA markers or short tandem repeats (STRs) are well-known hyper-variable genetic markers that have remarkable discrimination power for the evaluation of genetic diversity across various marine species (Hauser and Carvalho, 2008; An et al., 2011c, 2012; Blanco Gonzalez et al., 2012).

The present study aimed to characterize genetically the broodstock and offspring of a local government hatchery at Uljin, Korea, that releases the produced juveniles to the wild as a tool for stock enhancement, in order to determine whether current management strategy of hatchery stocks in a hatchery facility lead to reduced genetic variation of $P$. stellatus.

\section{MATERIAL AND METHODS}

\section{Sample collection and DNA extraction}

Samples of fin-clip tissue (approximately $1 \mathrm{~cm}^{3}$ ) were obtained from a local government hatchery at Uljin, Korea, in which the offspring of starry flounder to be released at several sites along the eastern coast are produced every year. At this facility, approximately 300 breeders between the ages of 2 and 5 years are maintained for reproduction. In 2008, 82 broodstock starry flounders were selected for reproduction according to sexual maturity and health condition. All these fishes were sampled. After the mating event, their offspring starry flounders were reared in a tank. Immediately before stocking, 50 offspring starry flounders were randomly sampled. In general, both wild-caught and captive-cultured sources of the broodstock were used for artificial reproduction. However, one hatchery manager informed that breeding has persisted for multiple generations with very little introduction of exotic broodstocks, due to the difficulty in collecting large numbers of sexually mature wild $P$. stellatus. No details regarding the founding and maintenance of the farmed strain are available; however, their original parents were held at a farm on the eastern coast of Korea. All samples were stored in $2 \mathrm{~mL} 99 \%$ ethanol at $4^{\circ} \mathrm{C}$ until DNA extraction. For genotyping, total DNA from fin-clips of each sample was extracted using a MagExtractor-Genomic DNA Purification Kit (TOYOBO, Osaka, Japan) by using an automated DNA extraction system, MagExtractor MFX-2100 (TOYOBO). The genomic DNA extracted was stored at $-20^{\circ} \mathrm{C}$ until genotyping.

\section{Microsatellite genotyping}

Nine highly variable microsatellite loci previously characterized (KPs1, KPs2, KPs15, 
KPs17A, KPs20, KPs25, KPs32, KPs33, and KPs36; An et al., 2011a) were selected for the present study (Table 1). A total of 132 starry flounders from the 2 populations were typed. Primer sequences, microsatellite repeat sequence, and the optimal annealing temperature for each locus are listed in Table 1. The forward primer from each primer set was 5'-fluorescent labeled with 1 of 3 dyes: 6-FAM, HEX, or NED (PE Applied Biosystems, Foster City, CA, USA). PCR amplification of 9 microsatellite loci was carried out using an RTC 200 instrument (MJ Research, Watertown, MA, USA) in $10 \mu \mathrm{L}$ solution containing 1050 ng DNA, 1X ExTaq buffer, $0.2 \mathrm{mM}$ dNTPs, 10 pmol each primer, and $0.25 \mathrm{U}$ Taq DNA polymerase (Takara, Shiga, Japan). The amplification protocol included an initial denaturation for $11 \mathrm{~min}$ at $95^{\circ} \mathrm{C}$, followed by 35 cycles of $1 \mathrm{~min}$ at $94^{\circ} \mathrm{C}, 1 \mathrm{~min}$ at the optimal annealing template listed in $\mathrm{An}$ et al. (2011a), and $1 \mathrm{~min}$ at $72^{\circ} \mathrm{C}$, with a final extension step of $5 \mathrm{~min}$ at $72^{\circ} \mathrm{C}$. For genotyping, $1 \mu \mathrm{L}$ PCR product was added to each reaction containing formamide with a size standard GeneScan-400HD [ROX] (Applied Biosystems) and electrophoresed using an ABI3130 DNA sequencer (Applied Biosystems). The fragment length of the PCR products was determined using the GeneMapper software (Version 4.0, Applied Biosystems).

\begin{tabular}{|c|c|c|c|c|}
\hline$\overline{\text { Locus }}$ & Repeat motif & Primer sequence $\left(5^{\prime} \rightarrow 3^{\prime}\right)$ & $\mathrm{Ta}\left({ }^{\circ} \mathrm{C}\right)$ & $\begin{array}{c}\text { GenBank } \\
\text { accession No }\end{array}$ \\
\hline KPs1 & $(\mathrm{CA})_{11}$ & $\begin{array}{l}\text { CAGCAGTAAGAGTGTGTCCTG hex } \\
\text { TTCAGCCTGTTTTCTGTCAT }\end{array}$ & 55 & EF157643 \\
\hline KPs2 & $(\mathrm{TG})_{12}$ & $\begin{array}{l}\text { TTAGGGGTGGGACAGACT hex } \\
\text { GTCATCAGATGGGAGAAAGAT }\end{array}$ & 55 & EF157644 \\
\hline KPs 15 & $(\mathrm{TG})_{5} \mathrm{TA}(\mathrm{TG})_{8} \mathrm{TC}(\mathrm{TG})_{4}$ & $\begin{array}{l}\text { GAGCCAGACCTCTCATGTTAC fam } \\
\text { CGCTTCCATGTGAACCAG }\end{array}$ & 60 & EF157648 \\
\hline KPs17A & $(\mathrm{TG})_{5} \mathrm{TC}(\mathrm{TG})_{9}$ & $\begin{array}{l}\text { CAACCACGTTATCCTCTGTG fam } \\
\text { CCAGAATAAATCTCATGCTCA }\end{array}$ & 60 & EF157649 \\
\hline KPs20 & $(\mathrm{CA})_{14}$ & $\begin{array}{l}\text { TGGGCAACTACGTACACACTA fam } \\
\text { GCCGACATTACAAAAACAAA }\end{array}$ & 58 & EF157651 \\
\hline KPs25 & $(\mathrm{TG})_{6} \mathrm{TA}(\mathrm{TG})_{8} \mathrm{TA}(\mathrm{TG})_{10}$ & $\begin{array}{l}\text { TGTTATCGGGTGTTGATTGT aned } \\
\text { GTTGATTGTGAAACGCTGTT }\end{array}$ & 60 & EF157653 \\
\hline KPs32 & $(\mathrm{TG})_{8} \mathrm{TT}(\mathrm{TG})_{7} \mathrm{TA}(\mathrm{TG})_{22}$ & $\begin{array}{l}\text { TTAAATAAGTGTCTGGGGATT hex } \\
\text { GCCACACTTCTGCTTCTG }\end{array}$ & 55 & EF157657 \\
\hline $\mathrm{KPs} 33$ & $(\mathrm{CA})_{9}-(\mathrm{CA})_{11}$ & $\begin{array}{l}\text { TTTCACTTCTCTTTGGGTTAC ned } \\
\text { GGCAGACTGATTCCTCATT }\end{array}$ & 60 & EF157658 \\
\hline KPs36 & $(\mathrm{TG})_{4} \mathrm{TT}(\mathrm{TG})_{13}$ & $\begin{array}{l}\text { ATGTGCCCAATAAAACAAAC hex } \\
\text { CTAAGCCCTAGAGCAAACAGT }\end{array}$ & 58 & EF157659 \\
\hline
\end{tabular}

\section{Statistical analyses}

The possible presence of null alleles and genotyping errors caused by stuttering and/or large-allele dropout were tested using MICRO-CHECKER (ver. 2.2.3; 1000 randomizations; van Oosterhout et al., 2004). To analyze the variation in microsatellite loci in the samples, the number of alleles per locus $\left(\mathrm{N}_{\mathrm{A}}\right)$, allelic richness $\left(\mathrm{A}_{\mathrm{R}}\right)$, allele size range $(\mathrm{S})$, and number of unique alleles $(\mathrm{U})$ were determined for each population at each locus by using the program FSTAT version 2.9.3.2 (Goudet, 1995). The $A_{R}$ measures the number of alleles independent of the sample size. The genetic heterozygosity between the population samples was estimated by calculating unbiased expected and observed heterozygosity values $\left(H_{E}\right.$ and $H_{O}$, respectively; Nei, 1978) by using the ARLEQUIN 3.0 (Excoffier et al., 2005) software. Differences in genetic diversity parameters were tested 
using nonparametric analysis (Wilcoxon signed-rank test; Wilcoxon, 1945). Deviations from Hardy-Weinberg equilibrium (HWE) at each locus were tested using a test analogous to the Fisher exact test by using the Markov-chain procedure of ARLEQUIN (the Markovchain parameters used were: steps, 100,000; dememorization, 10,000). ARLEQUIN was also used to assess linkage disequilibrium for all pairs of loci, whose empirical distribution is obtained by a permutation procedure (Slatkin and Excoffier, 1996). An inbreeding coefficient (Weir and Cockerham, 1984) was also estimated to measure the HWE departures evaluating the probabilities through random permutation procedures (minimum 10,000 permutations). Significance levels associated with the HWE analysis was adjusted for multiple tests by using the sequential Bonferroni correction technique (Rice, 1989). The genetic distance between populations was estimated on the basis of the chord distance, $D_{\mathrm{CE}}$ (Cavalli-Sforza and Edwards, 1967).

The extent of population subdivision was investigated by calculating fixation indices. Differentiation between populations was characterized using $F_{\mathrm{ST}}$ (Weir and Cockerham, 1984 ) and $R_{\mathrm{ST}}$ (Slatkin, 1995; Michalakis and Excoffier, 1996) estimates calculated using the computer program GENEPOP ver. 4.0 (http://kimura.univ-montp2.fr/ rousset/Genepop.htm). $R_{\mathrm{ST}}$ incorporates the correlation of the weighted mean allele size expressed as the number of tandem repeats. The sequential Bonferroni correction was applied to derive significance levels for the analysis involving multiple comparisons (Rice, 1989).

\section{RESULTS}

\section{Genetic diversity of the broodstock and their offspring samples}

Samples of 82 broodstock and 50 offspring P. stellatus collected from a hatchery, around the eastern coast of Korea, were screened for variation at the 9 polymorphic microsatellite loci. The 9 primer sets were polymorphic across the 2 Korean starry flounder populations studied, and the levels of polymorphisms (numbers and frequencies of alleles) varied depending on the locus. Reruns were conducted for approximately $20 \%$ of all individuals to ensure the reproducibility of allele scoring, and these replications produced identical results in each trial.

The MICRO-CHECKER analysis showed that most loci might have been influenced by one or more null alleles in both samples. Loci KPs1 and KPs20 appeared to be influenced in both the broodstock and their offspring samples, indicating that using loci KPs1 and KPs20 for population genetic analyses that assume HWE might prove to be problematic. Thus, a global multilocus $F_{\mathrm{ST}}$ value was estimated with and without these loci. However, factors existed that indicated that the other loci were affected by null alleles in only 1 sample. These loci were used in this study because there was no indication of an allele scoring error caused by stuttering and large-allele dropout. However, the presence of null alleles could be problematic for the estimates of Nei's genetic distance (Nei, 1978); thus, Cavalli-Sforza distance was used because this distance is less affected by null alleles (Chapuis and Estoup, 2006).

Genetic variability in each population is shown in Table 2. A total of 96 different alleles were observed over all 9 loci in the samples; the number of alleles varied from 4 at loci KPs20 to 17 at locus KPs25 and KPs32 (Table 2). Fewer alleles were found in the offspring population compared with those in the broodstock sample (Wilcoxon signed-rank test, $\mathrm{P}>$ 
0.05). The overall allelic richness varied from 5.97 to 13.53 (Table 2), with the broodstock population showing higher allelic richness than the offspring population (Wilcoxon signedrank test, $\mathrm{P}>0.05$ ). In total, 22 alleles were found to be unique to the broodstock population (Tables 2 and 3). Because the number of individuals analyzed differed between the populations, these results should be interpreted with caution. Despite these differences in genetic diversity, however, no clear difference in the average measures was observed between broodstock and their offspring samples (Wilcoxon signed-rank test, $\mathrm{P}>0.05$ ).

\begin{tabular}{|c|c|c|c|c|c|c|c|c|c|c|c|}
\hline \multirow[t]{2}{*}{ Population (No.) } & \multicolumn{11}{|c|}{ Microsatellite loci } \\
\hline & & KPs1 & KPs2 & KPs15 & KPs17A & KPs20 & KPs25 & KPs32 & KPs33 & KPs36 & Mean \\
\hline \multirow{5}{*}{ Broodstock (82) } & $F_{\mathrm{ST}}$ & 0.014 & 0.039 & 0.005 & 0.004 & 0.07 & 0.023 & 0.018 & 0.018 & 0.008 & 0.021 \\
\hline & $\mathrm{N}_{\mathrm{A}}$ & 11 & 8 & 8 & 8 & 9 & 17 & 17 & 8 & 10 & 10.67 \\
\hline & $\mathrm{A}_{\mathrm{R}}^{\mathrm{A}}$ & 9.62 & 7.01 & 7.68 & 7.94 & 7.95 & 15.76 & 15.05 & 7.99 & 9.76 & 9.86 \\
\hline & $\mathrm{S}^{\mathrm{R}}$ & $140-196$ & $138-166$ & $118-152$ & $68-84$ & $118-134$ & $204-332$ & $152-206$ & $274-294$ & $182-216$ & \\
\hline & $\mathrm{R}$ & 56 & 28 & 34 & 16 & 16 & 128 & 54 & 20 & 34 & \\
\hline \multirow{9}{*}{ Offspring (50) } & $\mathrm{U}$ & 4 & 1 & 1 & 0 & 5 & 6 & 5 & 0 & 2 & 2.67 \\
\hline & $H_{\mathrm{E}}$ & 0.806 & 0.576 & 0.712 & 0.751 & 0.602 & 0.868 & 0.857 & 0.74 & 0.756 & 0.741 \\
\hline & $H_{\mathrm{O}}^{\mathrm{E}}$ & 0.610 & 0.634 & 0.793 & 0.232 & 0.329 & 0.646 & 0.707 & 0.512 & 0.622 & 0.565 \\
\hline & $F_{\text {IS }}$ & $0.245^{*}$ & -0.103 & -0.114 & $0.693^{*}$ & $0.455^{*}$ & $0.256^{*}$ & 0.176 & $0.309^{*}$ & 0.178 & 0.034 \\
\hline & $N_{\mathrm{A}}$ & 7 & 7 & 7 & 8 & 4 & 11 & 12 & 8 & 8 & 8 \\
\hline & $A_{R}^{A}$ & 7 & 7 & 7 & 8 & 4 & 11 & 12 & 8 & 8 & 8 \\
\hline & $\mathrm{S}^{\mathrm{R}}$ & $140-170$ & $140-166$ & $118-146$ & $68-84$ & $120-130$ & $266-332$ & $154-206$ & $274-294$ & $182-216$ & \\
\hline & $\mathrm{R}$ & 30 & 26 & 28 & 16 & 10 & 66 & 52 & 20 & 34 & \\
\hline & $\mathrm{U}$ & 0 & 0 & 0 & 0 & 0 & 0 & 0 & 0 & 0 & 0 \\
\hline \multirow{7}{*}{ Mean all population } & $H_{\mathrm{E}}$ & 0.770 & 0.682 & 0.727 & 0.688 & 0.417 & 0.798 & 0.876 & 0.633 & 0.695 & 0.698 \\
\hline & $H_{0}^{\mathrm{E}}$ & 0.580 & 0.680 & 0.820 & 0.620 & 0.200 & 0.720 & 0.920 & 0.520 & 0.600 & 0.629 \\
\hline & $F_{\text {IS }}^{O}$ & $0.249^{*}$ & 0.002 & -0.129 & 0.100 & $0.523 *$ & 0.099 & -0.051 & 0.18 & 0.137 & 0.048 \\
\hline & $N_{\mathrm{A}}^{\mathrm{IS}}$ & 9 & 7.5 & 7.5 & 8 & 6.5 & 14 & 14.5 & 8 & 9 & 9.33 \\
\hline & $\mathrm{A}_{\mathrm{R}}^{\mathrm{A}}$ & 8.31 & 7 & 7.34 & 7.97 & 5.97 & 13.38 & 13.53 & 7.99 & 8.88 & 8.93 \\
\hline & $H_{\mathrm{E}}^{\mathrm{R}}$ & 0.788 & 0.629 & 0.720 & 0.720 & 0.510 & 0.833 & 0.867 & 0.687 & 0.726 & 0.72 \\
\hline & $H_{\mathrm{O}}^{\mathrm{E}}$ & 0.595 & 0.657 & 0.807 & 0.426 & 0.265 & 0.683 & 0.814 & 0.516 & 0.611 & 0.597 \\
\hline
\end{tabular}

No. of alleles per locus $\left(N_{\mathrm{A}}\right)$, allellic richness $\left(\mathrm{A}_{\mathrm{R}}\right)$, size in bp of alleles $(\mathrm{S})$, allelic size range $(\mathrm{R})$, No. of unique alleles $(\mathrm{U})$, expected heterozygosity $\left(H_{\mathrm{E}}\right)$, observed heterozygosity $\left(H_{\mathrm{O}}\right)$, and inbreeding coefficient $\left(F_{\mathrm{IS}}\right)$ are given for each population and locus. Calculations assume that individuals with one microsatellite band are homozygous for the allele. *Significant deviation from Hardy-Weinberg equibrium after Bonferroni's corrections (P, initial $\alpha=$ $0.05 / 9=0.006)$.

The $H_{\mathrm{O}}$ ranged from 0.265 at locus KPs20 to 0.814 at KPs32, whereas the $H_{\mathrm{E}}$ varied from 0.510 to 0.867 at the same loci (Table 2). In terms of heterozygosity, no significant difference was detected between the broodstock and offspring samples. Inbreeding coefficients $\left(F_{\text {IS }}\right)$ varied among markers from -0.129 (KPs15) to 0.523 (KPs20) in the offspring samples, and from -0.114 (KPs15) to 0.693 (KPs17A) in the broodstock samples. Average $F_{\text {IS }}$, including all markers, was 0.048 in the offspring sample and 0.034 in the broodstock sample.

Significant departures from HWE after Bonferroni correction $(\mathrm{P}<0.006)$ were found at 2 loci (KPs1 and KPs20) in the offspring samples, and at 5 loci (KPs1, KPs17A, KPs20, $\mathrm{KPs} 25$, and KPs33) in the broodstock samples, indicating that deviations from HWE were due to heterozygote deficiency.

The allele frequencies of all 9 microsatellites in each sample are shown in Table 3 and Figure 1. The allele frequency distributions indicated the presence of 28 rare alleles (frequency $<5 \%$ ) among a total of 72 alleles over all loci (mean $=38.9 \%$ ) in the offspring 
sample, whereas 53 rare alleles among a total of 96 alleles (mean $=55.2 \%)$ were observed in the broodstock sample. Rare alleles were detected at most loci and were not associated with a particular locus in either population. There was no significant linkage disequilibrium between loci pairs $(\mathrm{P}>0.05)$.

\begin{tabular}{|c|c|c|c|c|c|c|c|}
\hline Loci & Allele & Broodstock & Offspring & Loci & Allele & Broodstock & Offspring \\
\hline \multirow[t]{12}{*}{ KPs1 } & 140 & 0.018 & 0.010 & KPs 25 & 204 & 0.006 & 0.000 \\
\hline & 142 & 0.305 & 0.370 & & 266 & 0.024 & 0.020 \\
\hline & 144 & 0.006 & 0.000 & & 280 & 0.043 & 0.000 \\
\hline & 148 & 0.006 & 0.070 & & 282 & 0.091 & 0.070 \\
\hline & 150 & 0.043 & 0.100 & & 284 & 0.012 & 0.000 \\
\hline & 158 & 0.171 & 0.060 & & 286 & 0.018 & 0.070 \\
\hline & 164 & 0.232 & 0.250 & & 290 & 0.030 & 0.020 \\
\hline & 168 & 0.012 & 0.000 & & 294 & 0.091 & 0.280 \\
\hline & 170 & 0.091 & 0.140 & & 298 & 0.104 & 0.040 \\
\hline & 174 & 0.110 & 0.000 & & 308 & 0.030 & 0.030 \\
\hline & 196 & 0.006 & 0.000 & & 310 & 0.018 & 0.030 \\
\hline & & & & & 314 & 0.067 & 0.000 \\
\hline \multirow[t]{9}{*}{ KPs2 } & 138 & 0.018 & 0.000 & & 316 & 0.006 & 0.000 \\
\hline & 140 & 0.006 & 0.010 & & 322 & 0.299 & 0.330 \\
\hline & 144 & 0.140 & 0.090 & & 324 & 0.012 & 0.000 \\
\hline & 146 & 0.616 & 0.450 & & 330 & 0.061 & 0.090 \\
\hline & 148 & 0.165 & 0.330 & & 332 & 0.085 & 0.020 \\
\hline & 150 & 0.037 & 0.060 & & & & \\
\hline & 152 & 0.006 & 0.020 & KPs32 & 152 & 0.006 & 0.000 \\
\hline & 166 & 0.012 & 0.040 & & 154 & 0.030 & 0.050 \\
\hline & & & & & 156 & 0.098 & 0.100 \\
\hline \multirow[t]{9}{*}{ KPs15 } & 118 & 0.250 & 0.180 & & 158 & 0.030 & 0.000 \\
\hline & 120 & 0.018 & 0.010 & & 172 & 0.006 & 0.000 \\
\hline & 124 & 0.018 & 0.010 & & 174 & 0.006 & 0.000 \\
\hline & 126 & 0.445 & 0.420 & & 176 & 0.165 & 0.120 \\
\hline & 128 & 0.152 & 0.250 & & 178 & 0.274 & 0.130 \\
\hline & 132 & 0.085 & 0.070 & & 180 & 0.055 & 0.090 \\
\hline & 146 & 0.018 & 0.060 & & 182 & 0.012 & 0.010 \\
\hline & 152 & 0.012 & 0.000 & & 194 & 0.159 & 0.210 \\
\hline & & & & & 196 & 0.012 & 0.050 \\
\hline \multirow[t]{9}{*}{ KPs17A } & 68 & 0.018 & 0.030 & & 198 & 0.030 & 0.000 \\
\hline & 70 & 0.201 & 0.110 & & 200 & 0.037 & 0.040 \\
\hline & 72 & 0.061 & 0.010 & & 202 & 0.018 & 0.010 \\
\hline & 74 & 0.037 & 0.030 & & 204 & 0.055 & 0.180 \\
\hline & 76 & 0.055 & 0.020 & & 206 & 0.006 & 0.010 \\
\hline & 78 & 0.427 & 0.510 & & & & \\
\hline & 82 & 0.134 & 0.180 & KPs33 & 274 & 0.079 & 0.070 \\
\hline & 84 & 0.067 & 0.110 & & 280 & 0.451 & 0.560 \\
\hline & & & & & 282 & 0.061 & 0.010 \\
\hline \multirow[t]{16}{*}{ KPs20 } & 118 & 0.012 & 0.000 & & 284 & 0.037 & 0.020 \\
\hline & 120 & 0.024 & 0.060 & & 286 & 0.128 & 0.220 \\
\hline & 122 & 0.024 & 0.010 & & 288 & 0.177 & 0.050 \\
\hline & 124 & 0.006 & 0.000 & & 292 & 0.037 & 0.060 \\
\hline & 126 & 0.006 & 0.000 & & 294 & 0.030 & 0.010 \\
\hline & 128 & 0.506 & 0.740 & & & & \\
\hline & 130 & 0.378 & 0.190 & KPs36 & 182 & 0.445 & 0.510 \\
\hline & 132 & 0.024 & 0.000 & & 184 & 0.073 & 0.030 \\
\hline & 134 & 0.018 & 0.000 & & 188 & 0.152 & 0.140 \\
\hline & & & & & 190 & 0.098 & 0.010 \\
\hline & & & & & 192 & 0.079 & 0.050 \\
\hline & & & & & 194 & 0.012 & 0.000 \\
\hline & & & & & 196 & 0.067 & 0.120 \\
\hline & & & & & 198 & 0.018 & 0.000 \\
\hline & & & & & 214 & 0.030 & 0.120 \\
\hline & & & & & 216 & 0.024 & 0.020 \\
\hline
\end{tabular}



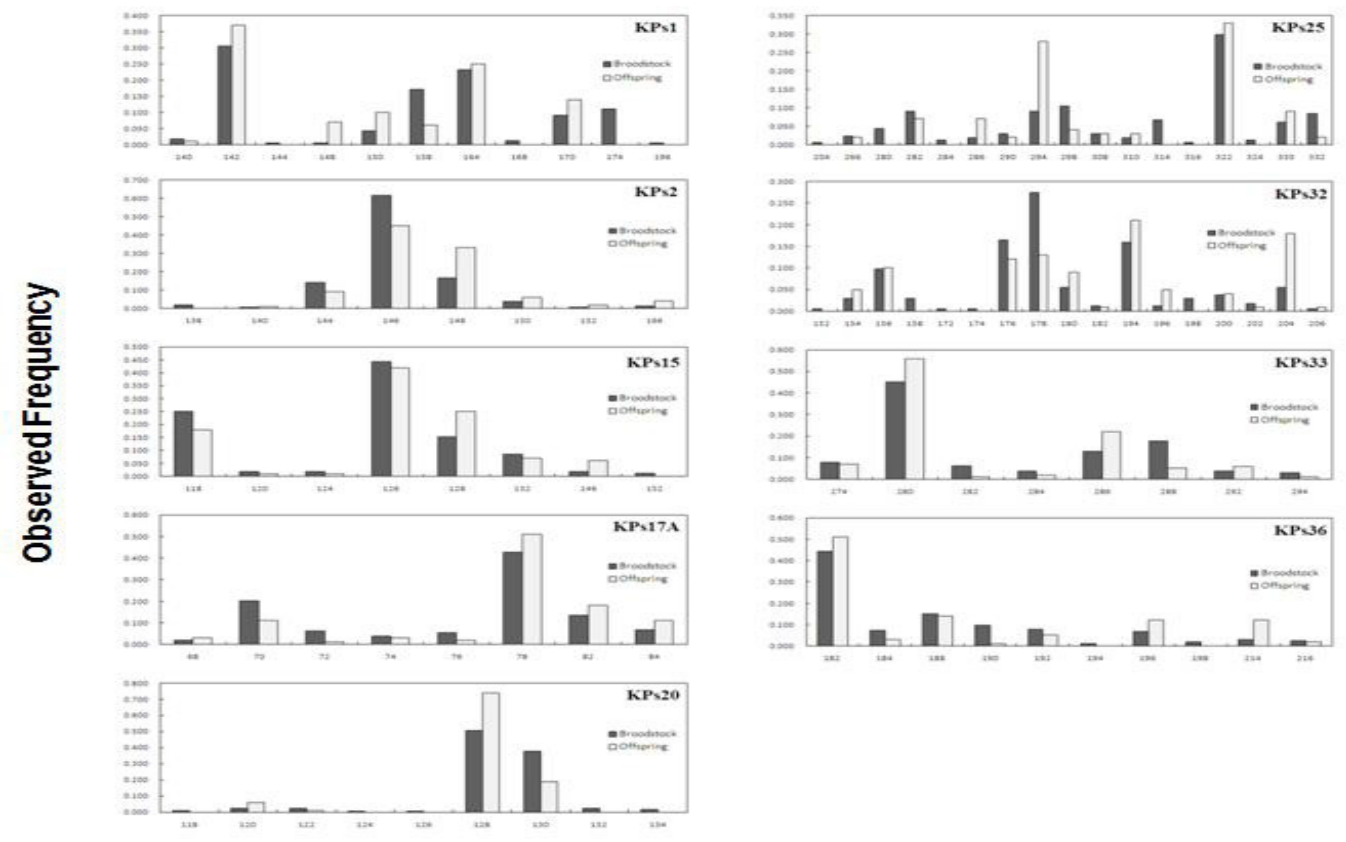

Allele size (bp)

Figure 1. Allele size frequency distributions of the nine microsatellite loci of Platichthys stellatus used in this study.

\section{Genetic variation between samples}

Genetic differentiation between broodstock and offspring populations in a hatchery was estimated using $F_{\mathrm{ST}}$ and $R_{\mathrm{ST}}$ estimates. The global multilocus $F_{\mathrm{ST}}$, including all loci, was estimated to be $0.021(\mathrm{P}<0.01)$, and the $R_{\mathrm{ST}}$ value was $0.026(\mathrm{P}<0.01) . F_{\mathrm{ST}}$ estimates were significantly different between broodstock and offspring populations irrespective of whether the 2 loci with potential null alleles (KPs1 and KPs20) were included. When 2 loci were excluded, the global multilocus $F_{\mathrm{ST}}$ was estimated to be $0.016(\mathrm{P}<0.01)$, and the $R_{\mathrm{ST}}$ value was $0.027(\mathrm{P}<0.01)$. The significant $F_{\mathrm{ST}}$ and $R_{\mathrm{ST}}$ estimates indicate genetic differentiation between these broodstock and their offspring starry flounder samples.

\section{DISCUSSION}

In this study, the genetic variation of hatchery stock samples of $P$. stellatus (mean $N_{\mathrm{A}}=$ 9.33 and mean $H_{\mathrm{E}}=0.72$ ) was lower than the reported ones (mean $N_{\mathrm{A}}=19.96 \pm 6.6$, mean $H_{\mathrm{E}}$ $=0.77 \pm 0.19$ averaged from 12 species) for other marine fish species (DeWoody and Avise, 2000). Similar genetic variability has been reported for these species as well as for another marine species, the Korean black rockfish, which might indicate that these demersal fish are less diverse compared to other migratory fishes (An et al., 2011a,c).

When the level of diversity in offspring population was compared with that in the broodstock samples, no significant difference in the average $N_{\mathrm{A}}$ per locus or average $H_{\mathrm{E}}$ was 
observed. However, on average, $81.1 \%$ of the allelic richness observed within the broodstock samples was present in the offspring samples, and the offspring population showed a slightly lower level of heterozygosity. Reduction of genetic variability in hatchery populations compared to a broodstock or a natural population has been reported in other cultivated fish species (Porta et al., 2006). The results of this study were consistent with these findings. In these reports, the cause of reduction of genetic variability was inferred to be the actual number of parents contributing to the offspring being less than that of the total broodstock or natural population available. Tessier et al. (1997) reported an extreme case in which stocked offspring caused major genetic drift and a 50\% reduction in effective population size of a wild Atlantic salmon population. No detailed information was available regarding the number of parents that actually contributed to the production of the offspring used in this study. Thus, the results obtained should be evaluated with caution.

Significant deviations from HWE in the direction of deficiencies of heterozygotes were detected in both the broodstock and their offspring samples, even after sequential Bonferroni's correction for multiple tests. A similar phenomenon was also observed in a previous microsatellite analysis (Ortega-Villaizán Romo et al., 2005). Null or non-amplifying alleles could possibly account for the heterozygote deficiencies in the data. Indeed, our MICROCHECKER analysis revealed the presence of null alleles at most loci, with a significant heterozygote deficit. The presence of null alleles has also been reported for numerous other fishery animals (Frankham et al., 2002; Keller and Waller, 2002). However, admixture of more than 2 independent populations, nonrandom mating, or artificial selection forces during seed production and cultivation might account for the deviation from HWE in both the broodstock and their offspring populations.

There was significant genetic differentiation detected by $F_{\mathrm{ST}}$ and $R_{\mathrm{ST}}$ values between the broodstock and offspring starry flounder samples. This difference is likely to be a result of the reduction in the effective number of contributing parents. Considering that this study was limited by the number of populations screened, the genetic diversity parameters for each population might be explained by the data from additional populations. Therefore, our results should be interpreted with caution. Further study is required to assess the influence of the standard breeding practices in a hatchery of this important fishery species.

The preservation of genetic variation is an important consideration in maintaining any hatchery stock to provide fish to maintain wild populations. Continued intensive breeding practices for stock enhancement might lead to decreased genetic variability if the number of effective breeders is not maintained. Maintenance of levels of genetic variation within hatchery stocks comparable to wild source populations requires good broodstock management practices. In hatchery strains, use of unrelated fish from the wild as broodstock is generally recommended because they can produce offspring that have a higher fitness in the wild than offspring from older, domesticated hatchery stocks, even though first-generation hatchery fish still have reduced fitness in the wild (Christie et al., 2012). However, this is often difficult to achieve due to economic constraints. Instead, a subset of hatchery-based fish is normally used as broodstock. Historically, hatchery managers preferred the use of fish born in hatcheries as broodstock to create future generations, because whatever trait they had that allowed them to succeed in the hatchery helped produce thousands of apparently healthy young offspring. However, this practice can have unintentional negative effects on the genetic variability of the broodstock (Allendorf and Pyman, 1987). Parental similarity is negatively related to adult re- 
productive success, and that, wherever sample sizes are large, the relationships become significantly negative (Amos et al., 2001). Thus, periodically introducing new genetic material from local wild stocks is necessary. This infusion would preserve the starry flounder gene pool and would enable hatchery production of fish that could perform well when returned to the wild. In addition, even if founder specimens of broodstock are genetically intact, lack of a proper management strategy can lead to inbreeding and rapid decline in diversity at the gene level. Hence, continued genetic monitoring of bloodstock is warranted in artificial seed production.

A desirable characteristic of a stock enhancement program is to release genetically similar fish to a wild population or a broodstock containing unrelated fish from the wild. For Korean starry flounder, many rare alleles at 9 microsatellite DNA loci were found in the broodstock and some were not observed in the progeny produced for release. Probability of loss of rare alleles is very high (Allendorf, 1986), and all alleles lost in the offspring were rare alleles. In fact, the loss of alleles is more important than the change in allele frequencies, because the latter can be changed again by random drift, but a lost allele cannot be recovered. For the proper management of stock enhancement programs, production of progeny should be based on well-organized broodstock management strategies. Genetic factors are of vital importance in the production of good quality seed of marine animals for stocking in the sea. Genetic integrity of wild populations should be protected from the impact of hatchery releases through a carefully planned broodstock management strategy. Unknown and known genetic changes and possible loss of genetic variation in broodstock and progeny should be monitored. Molecular tools such as nuclear DNA markers are a good monitoring tool for broodstock management. This information will be useful to evaluate the feasibility of the enhancement program to maintain the genetic diversity of the wild population as well as to improve the management of the hatchery for the following season.

In summary, genetic diversity analysis revealed changes in the genetic composition between the broodstock and offspring starry flounder populations in a hatchery in Korea. The offspring starry flounder produced for release in a stock enhancement program showed some level of genetic differentiation, compared with the broodstock samples. Thus, for an adequate stocking strategy of starry flounder, periodic genetic evaluations of bloodstock, progeny, and target populations are necessary. Such genetic monitoring can be useful for the preservation and further genetic management of the Korean starry flounder.

\section{ACKNOWLEDGMENTS}

Research supported by a grant from the National Fisheries Research and Development Institute (NFRDI; contribution number \#RP-2013-BT-080). The views expressed herein are those of the authors and do not necessarily reflect the views of NFRDI.

\section{REFERENCES}

Allendorf FW (1986). Genetic drift and the loss of alleles versus heterozygosity. Zoo Biol. 5: 181-190.

Allendorf FW and Pyman N (1987). Genetic Management of Hatchery Stocks. In: Population Genetics and Fishery Management (Ryman N and Utter F, eds.). University of Washington Press, Seattle, 141-159.

Amos W, Wilmer JW, Fullard K, Burg TM, et al. (2001). The influence of parental relatedness on reproductive success. Proc. R. Soc. London B 268: 2021-2027.

An HS, Byun SG, Kim YC, Lee JW, et al. (2011a). Wild and hatchery populations of Korean starry flounder (Platichthys stellatus) compared using microsatellite DNA markers. Int. J. Mol. Sci. 12: 9189-9202. 
An HS, Hong SW, Kim EM and Myeong JI (2011b). Comparative genetic diversity of wild and hachery populations of Korean threadsail filefish Stephanolepis cirrhifer using cross-species microsatellite markers. Genes Genomics 33: 605-611.

An HS, Kim EM, Lee JH, Noh JK, et al. (2011c). Population genetic structure of wild and hatchery black rockfish Sebastes inermis in Korea, assessed using cross-species microsatellite markers. Genet. Mol. Res. 10: 2492-2504.

An HS, Lee JW and Dong CM (2012). Population genetic structure of Korean pen shell (Atrina pectinata) in Korea inferred from microsatellite marker analysis. Genes Genomics 34: 681-688.

An HS, Lee JW, Park JY and Jung HT (2013). Genetic structure of the Korean black scraper Thamnaconus modestus inferred from microsatellite marker analysis. Mol. Biol. Rep. 40: 3445-3456.

Blanco Gonzalez E, Aritaki M and Taniguchi N (2012). Microsatellite multiplex panels for population genetic analysis of red sea bream Pagrus major. Fish. Sci. 78: 603-611.

Cavalli-Sforza LL and Edwards AWF (1967). Phylogenetic analysis, models and estimation procedures. Evolution 21: 550-570.

Chapuis MP and Estoup A (2006). Microsatellite null alleles and estimation of population differentiation. Mol. Biol. Evol. 24: 621-631.

Christie MR, Marine ML, French RA and Blouin MS (2012). Genetic adaptation to captivity can occur in a single generation. Proc. Natl. Acad. Sci. U. S. A. 109: 238-242.

DeWoody JA and Avise JC (2000). Microsatellite variation in marine, freshwater and anadromous fishes compared with other animals. J. Fish Biol. 56: 461-473.

Excoffier L, Laval G and Schneider S (2005). Arlequin (version 3.0): an integrated software package for population genetics data analysis. Evol. Bioinform. Online 1: 47-50.

Frankham R, Ballou J and Briscoe D (2002). Introduction to Conservation Genetics. Cambridge University Press, Cambridge.

Goudet J (1995). FSTAT: a computer program to calculate F-statistics. J. Hered. 86: 485-486.

Han HS, Nam BH, Kang JH, Kim YK, et al. (2012). Genetic variation in wild and cultured populations of the sea squirt Halocynthia roretzi inferred from microsatellite DNA analysis. Fish. Aquat. Sci. 15: 151-155.

Hauser L and Carvalho GR (2008). Paradigm shifts in marine fisheries genetics, ugly hypotheses slain by beautiful facts. Fish Fish. 9: 333-362.

Hong SE, Kim JK, Yu JN, Kim KY, et al. (2012). Genetic variation in the Asian shore crab Hemigrapsus sanguineus in Korean coastal waters as inferred from mitochondrial DNA sequences. Fish. Aquat. Sci. 15: 49-56.

Kang DY, Lee JH, Kim WJ and Kim HC (2012). Morphological specificity in cultured starry flounder Platichthys stellatus reared in artificial facility. Fish. Aquat. Sci. 15: 117-123.

Keller LF and Waller DM (2002). Inbreeding effects in wild populations. Trends Ecol. Evol. 17: 230-241.

KFRA, (Korean Fisheries Resources Agency) (2010). Evaluation of a Stock Enhancement Programme Effectiveness. Korean Fisheries Resources Agency, Seoul, Korea.

Kohlmann K, Kersten P and Flajshans M (2005). Microsatellite-based genetic variability and differentiation of domesticated, wild and feral common carp (Cyprinus carpio L.) populations. Aquaculture 247: 253-266.

Lee HJ and Hur SB (2012). Comparison between phylogenetic relationships based on 18S rDNA sequences and growth by salinity of Chlorella-like species (Chlorophyta). Fish. Aquat. Sci. 15: 125-135.

Michalakis Y and Excoffier L (1996). A genetic estimation of population subdivision using distances between alleles with special reference for microsatellite loci. Genetics 142: 1061-1064.

NFRDI (National Fisheries Research and Development Institute) (2010). Manual of Starry Flounder Culture. National Fisheries Research and Development Institute, Busan.

Nei M (1978). Estimation of average heterozygosity and genetic distance from a small number of individuals. Genetics 89: $583-590$

Ortega-Villaizán Romo MM, Suzuki S, Ikeda M, Nakajima M, et al. (2005). Monitoring of the genetic variability of the hatchery and recaptured fish in the stock enhancement program of the rare species barfin flounder Verasper moseri. Fish. Sci. 71: 1120-1130.

Porta J, Porta JM, Martínez-Rodríguez G and Alvarez MC (2006). Genetic structure and genetic relatedness of a hatchery stock of Senegal sole (Solea senegalensis) inferred by microsatellites. Aquaculture 251: 46-55.

Rice WR (1989). Analyzing tables of statistical tests. Evolution 43: 223-225.

Slatkin M (1995). A measure of population subdivision based on microsatellite allele frequencies. Genetics 139: 457-462.

Slatkin M and Excoffier L (1996). Testing for linkage disequilibrium in genotypic data using the Expectation-Maximization algorithm. Heredity 76 (Pt 4): 377-383.

Tessier N, Bernatchez L and Wright JM (1997). Population structure and impact supportive breeding inferred from mitochondrial and microsatellite DNA analyses in land-locked Atlantic salmon Salmo salar L. Mol. Ecol. 6: 735-750. 
van Oosterhout C, Hutchinson WF, Wills DPM and Shipley P (2004). MICRO-CHECKER: software for identifying and correcting genotyping errors in microsatellite data. Mol. Ecol. Notes 4: 535-538.

Wang L, Meng Z, Liu X, Zhang Y, et al. (2011). Genetic diversity and differentiation of the orange-spotted grouper (Epinephelus coioides) between and within cultured stocks and wild populations inferred from microsatellite DNA analysis. Int. J. Mol. Sci. 12: 4378-4394.

Weir BS and Cockerham CC (1984). Estimating F-statistics for the analysis of population structure. Evolution 38: 13581370.

Wilcoxon F (1945). Individual comparisons by ranking methods. Biometrics Bull. 1: 80-83.

Yoon MG, Jung JY, Nam YK and Kim DS (2011). Genetic diversity of thread-sail filefish Stephanolepis cirrhifer populations in Korean coastal waters inferred from mitochondrial DNA sequence analysis. Fish. Aquat. Sci. 14: 16-21. 